\title{
The resonant response of the ionosphere imaged after the 2011 off the Pacific coast of Tohoku Earthquake
}

\author{
Lucie M. Rolland ${ }^{1}$, Philippe Lognonné ${ }^{1}$, Elvira Astafyeva ${ }^{1}$, E. Alam Kherani ${ }^{2}$, \\ Naoki Kobayashi ${ }^{3}$, Michèle Mann ${ }^{1}$, and Hiroshi Munekane ${ }^{4}$ \\ ${ }^{1}$ Institut de Physique du Globe de Paris, Sorbonne Paris Cité, Univ. Paris Diderot, UMR 7154 CNRS, F-94100 Saint-Maur, France \\ ${ }^{2}$ Instituto Nacional de Pesquisais Espaciais (INPE), São Jose dos Campos, São Paulo, BR-12227010, Brazil \\ ${ }^{3}$ Institute of Space and Astronautical Science, Japan Aerospace Exploration Agency, \\ 3-1-1 Yoshinodai, Chuo-ku, Sagamihara City, Kanagawa 252-5210, Japan \\ ${ }^{4}$ Geospatial Information Authorithy of Japan, 1 Kitasato, Tsukuba 305-0811, Japan
}

(Received April 11, 2011; Revised June 10, 2011; Accepted June 11, 2011; Online published September 27, 2011)

\begin{abstract}
We provide here a preliminary analysis of the ionospheric perturbations observed after the 11 March 2011 Tohoku Earthquake using a GPS-derived Total Electron Content (TEC) technique. Such anomalies are routinely observed after seismic events of magnitude $M_{\mathrm{w}}=6$ and more. Here, we use the high density and the wide coverage of the Japanese Global Positioning System (GPS) network GEONET to image the ionosphere just after the main shock. We describe ionospheric perturbations with exceptional extension in amplitude and duration. As already seen in earlier events, a first intense signal is observed about 10 minutes after the seismic rupture; the first response consists in two modes: one propagating beyond $3 \mathrm{~km} / \mathrm{s}$ and the other at nearly $1 \mathrm{~km} / \mathrm{s}$. A further analysis of TEC time series of the latter mode near the source shows the typical frequencies of acoustic resonance. Beyond $400 \mathrm{~km}$ from the source, both the tsunami induced gravity wave and a third mode are imaged, the latter for the first time. We show that the pattern of this slow $(225 \mathrm{~m} / \mathrm{s} \pm 10 \mathrm{~m} / \mathrm{s})$ and long period gravity wave $(1.8 \pm 0.2$ $\mathrm{mHz}$ ) is most visible in the North-West of the epicentral area. This description is corroborated by a computation of the normal modes of the solid Earth-atmosphere system.
\end{abstract}

Key words: GPS-TEC, earthquake, ionosphere, acoustic resonance.

\section{Introduction}

The 11 March 2011 Tohoku Earthquake is a major seismic event $\left(M_{\mathrm{w}}=9.0\right)$ that ruptured at 05:46:23 UT along a thrust fault at the east coast of Honshu (Japan) and triggered a powerful tsunami of more than 10 meters in height, causing severe and catastrophic damages. USGS also reports that the epicenter of this shallow earthquake is estimated at a $32 \mathrm{~km}$ depth and located at $38.32^{\circ} \mathrm{N}$ and $142.37^{\circ} \mathrm{E}$. Japan is instrumented with the widest and densest network of continuous Global Positioning System (GPS) receivers, the Japanese GPS network GEONET (see Fig. 1). GPS can be used to monitor the Total Electron Content (TEC) that is a measurement of an integrated value of the ionospheric electron density along a satellite-receiver line-of-sight (in TEC units TECU $10^{16}$ electrons $/ \mathrm{m}^{2}$ ). As documented by Lognonné et al. (2006) and Rolland et al. (2011), this technique is now frequently used for detection of an ionospheric signature of seismic events of magnitude 6 and more.

In the case of wide dense GPS networks like in California and Japan, ionospheric waves can be imaged dynamically. In particular, ionospheric signatures of class $M=8$ earthquakes were imaged near the source (Heki and Ping, 2005; Astafyeva and Heki, 2009; Astafyeva et al., 2009)

Copyright (c) The Society of Geomagnetism and Earth, Planetary and Space Sciences (SGEPSS); The Seismological Society of Japan; The Volcanological Society of Japan; The Geodetic Society of Japan; The Japanese Society for Planetary Sciences; TERRAPUB. and also far from the source (Dučić et al., 2003; Rolland et $a l ., 2011)$. For seismic sources, two kinds of waves were identified in a close vicinity of an epicenter: waves propagating at the typical sound speed at ionospheric heights (from 0.6 to $1 \mathrm{~km} / \mathrm{s}$ ) and waves propagating beyond $3 \mathrm{~km} / \mathrm{s}$. The first kind is related to the acoustic plume emitted by the piston-like effect of the Earth's surface oscillations on the surrounding atmosphere, and modeled using seismic ray tracing (Heki and Ping, 2005) following Calais et al. (1998), or normal modes (Kobayashi et al., 2009). The second kind of waves is induced by the Rayleigh waves propagating at about $3.5 \mathrm{~km} / \mathrm{s}$ (Astafyeva et al., 2009; Rolland et al., 2011). See Lognonné et al. (1998) for a more complete theoretical description of these waves and Dautermann et al. (2009) for the case of atmospheric source instead of earthquake excitation.

The high quality data acquired the day of the 2011 Tohoku event will undoubtedly carry on new insights on the mechanisms of generation of these waves as well as information on the seismic rupture itself. We present here ionospheric images observed after the earthquake and focus our paper on the analysis of long duration acoustic waves, the tsunami induced gravity waves and on a third mode emitted by the seismic source. This latter was, to our knowledge, never imaged so widely and with such a high signal to noise ratio in the ionosphere. 


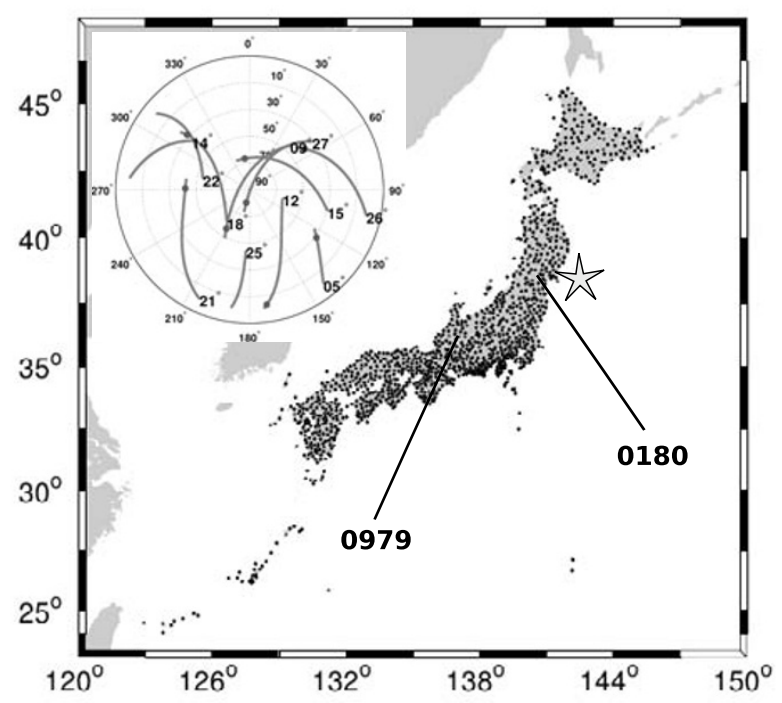

Fig. 1. Map of the GEONET dense GPS receivers network where the location of the epicenter of the Tohoku Earthquake is marked by a star. The polar view of the elevation and azimuth angles of the GPS satellites from 5:30 UT to 8:30 UT as seen by receiver 0979 (shown on the map) is plotted in the inner panel. The dots indicate the satellite geometry at the seismic origin time.

\section{Data Processing and Observations}

30s sampled data were downloaded from the GEONET public ftp site (ftp://163.42.5.1). Following the same methodology as Rolland et al. (2011), a 1 to $10 \mathrm{mHz}$ bandpass Finite Impulse Response (FIR) butterworth filter is applied in order to remove the contributions of the daily ionospheric variability, the satellites motion and the instrumental biases. For representation purpose, we locate the TEC measurement at the intersection of the line-of-sight and an ionospheric thin layer whose height is chosen near the peak of electron density, here $250 \mathrm{~km}$. This allows us to map the observed perturbations in so-called "TEC maps". A movie of TEC maps from 5:30 to 9:00 UT is made available online at http://ganymede.ipgp.fr/ tohoku/ (movie 1) with a movie of TEC ionospheric perturbations observed offshore Hawaii after this same event (movie 2). See Makela et al. (2011) and Occhipinti et al. (2011) for details on Hawaii observations.

On March 11th, we observe ionospheric perturbations with exceptional extension in amplitude and duration, using more than 10 satellites while one day before the earthquake (10th March) at the same GPS interval, the data acquired by GEONET do not show any significant perturbation. We are thus confident that the significant waves observed here are related to the earthquake. The large amplitude (a few TECU peak-to-peak) proves that strong vertical displacements occurred along the fault. The two modes described in the introduction are visible on the TEC travel-time diagram of satellite 15 (see Fig. 2(b)). Note that the first fast propagating wave (more than $3 \mathrm{~km} / \mathrm{s}$, plain grey line) is particularly well detected by satellite 26 . Its detailed analysis will require however 1-second sampled GEONET data, as the 30-seconds sampling is unable to record at close epicentral distances without aliasing (Rolland et al., 2011). Waves propagating at around $1 \mathrm{~km} / \mathrm{s}$ are also detected (dashed grey line). The first arrival of them takes the form of a N-shaped wave and is observed at first about 10 minutes after the main shock. These features are similar to the previous observations detailed in the introduction.

On Fig. 3, we show the time series and the corresponding spectrograms for satellites 15 and 22 observed by station 0979 and 0180, respectively (see their locations on Fig. 1).

\subsection{Acoustic resonance}

As seen on satellite-station 15-0979 time series (Fig. 3), the duration of the first and sharp $\mathrm{N}$ wave exceeds $10 \mathrm{~min}-$ utes and is propagating at nearly $1 \mathrm{~km} / \mathrm{s}$. A 2 hours long ringing signal follows, characterized by frequencies located at about $3.7 \mathrm{mHz}$ and $4.4 \mathrm{mHz}$, corresponding to the fundamental and first harmonic of the atmospheric trapped acoustic modes (Lognonné et al., 1998; Kobayashi, 2007).

This wave was observed once at isolated locations after the Sumatra giant earthquake $(M=9.2)$ and the following tsunami of December 2004 (Choosakul et al., 2009) but never imaged so clearly by GPS-TEC technique. The $3.7 \mathrm{mHz}$ waves have also been reported after convective storms (Georges, 1973). The interaction of the spheroidal surface waves with the atmosphere also leads to high sensitivity of the spheroidal modes ${ }_{0} S_{27} / 0 S_{29}$ and ${ }_{0} S_{34} / 0 S_{37}$, whose frequencies are close to 3.69 and $4.35 \mathrm{mHz}$, respectively. These modes were excited by a source of the bichromatic excitation on the Pinatubo eruption (Kanamori and Mori, 1992; Lognonné, 2009).

Figure 4 shows the dispersion curve of the acoustic trapped modes modeled using a one dimensional normal modes theory applied to the solid Earth (PREM model, Dziewonski and Anderson, 1981) surrounded by a realistic atmosphere (MSISE-00, Picone et al., 2002). This full Earth model allows a computation of all kinds of normal modes and therefore of seismic and tsunami modes (with their energy mainly located in the solid Earth and ocean) and of atmospheric acoustic and gravity modes with their energy predominantly located in the atmosphere but related to a compression energy and gravitational one respectively. Note that the depth of the ocean in PREM is $3 \mathrm{~km}$, comparable to the bathymetry off the coast of Japan (2 to $3.5 \mathrm{~km}$ ), and the MSISE atmosphere is computed for the local time and location of the observations since the efficiency of the solid Earth-atmosphere coupling depends on atmospheric conditions (Rolland et al., 2011).

The acoustic trapped modes, computed following Lognonné et al. (1998) are found in the range $3.7-3.8 \mathrm{mHz}$ and 4.35-4.48 mHz (Fig. 4(b)) for angular orders smaller than $\ell=170$ and wavelength larger than about $235 \mathrm{~km}$. They have quality factors $Q$ of about 150 and 20 respectively, meaning that the first ones are less attenuated than the second ones. This can explain why, in the spectrogram for satellite 15 observed by station 0979 (Fig. 3(a)), the 3.7$3.8 \mathrm{mHz}$ resonance lasts longer than the $4.35-4.48 \mathrm{mHz}$ resonance.

\subsection{Atmospheric gravity waves and tsunami pattern}

Travel-time diagrams of satellite 15, 21 and 22 show a third type of wave, aligned along the $225 \mathrm{~m} / \mathrm{s}( \pm 10 \mathrm{~m} / \mathrm{s})$ slope (magenta plain line). On the snapshots in Fig. 2(c)), these waves appear at about $400 \mathrm{~km}$ of epicentral distance. They then propagate as concentric waves (with respect to 

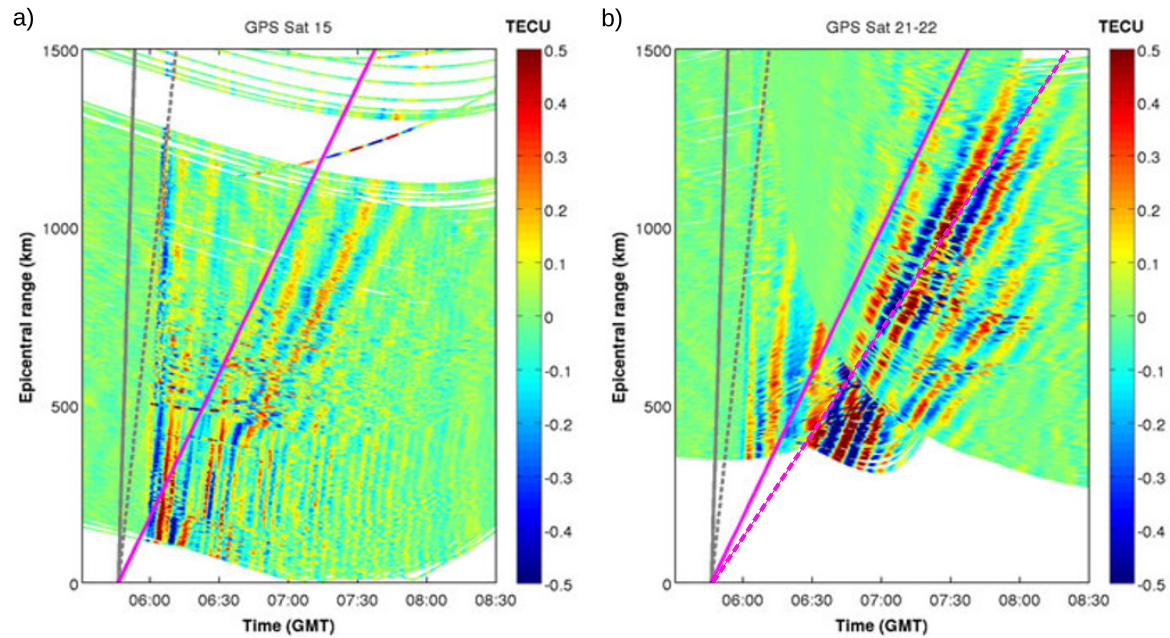

c) 06:43:00 07:01:30
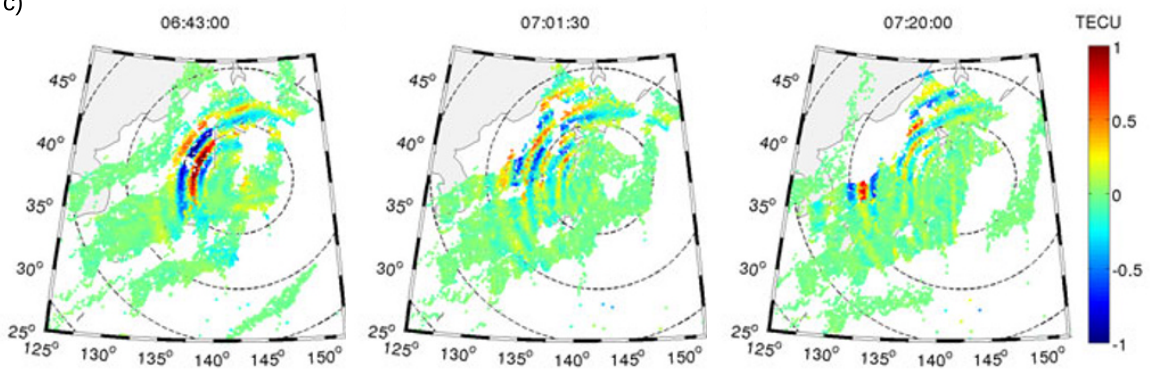

Fig. 2. (a) and (b) Travel-time diagrams of slant TEC time series filtered from 1 to $10 \mathrm{mHz}$ for satellites 15 and $21-22$ respectively, as observed by the GPS receivers of GEONET. The plain grey line has a $3.5 \mathrm{~km} / \mathrm{s}$ slope, the dashed grey line $1 \mathrm{~km} / \mathrm{s}$, the magenta plain line $225 \mathrm{~m} / \mathrm{s}$ and the dashed magenta line of the panel (b) $171 \mathrm{~m} / \mathrm{s}$. Those four lines all have an origin at the seismic origin time and should be shifted by the time of arrival of the wave at the maximum of ionization to correspond to real travel-time diagrams. (c) Sample of filtered TEC maps showing the gravity wave emitted by the rupture. Dashed circles are centered on the epicenter location and drawn every $500 \mathrm{~km}$. A movie containing the whole sequence of ionospheric anomalies observed after the earthquake (from 5:30 UT to 9:00 UT) can be viewed at the following link: http://ganymede.ipgp.fr/ tohoku/ (movie1).

a)

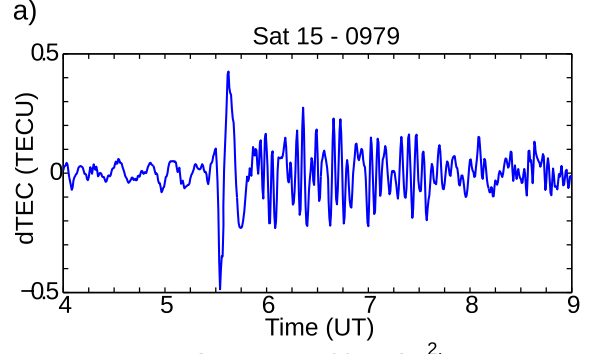

DSP $\max =1.60 \mathrm{TECU}^{2} / \mathrm{s}$

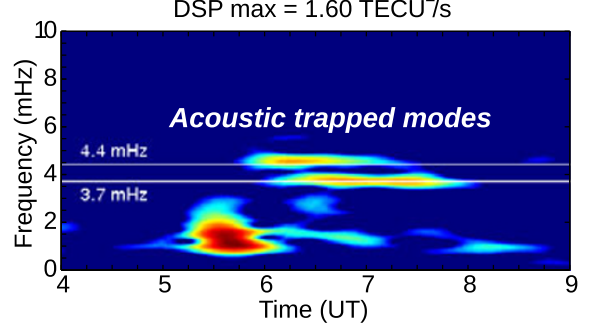

b)

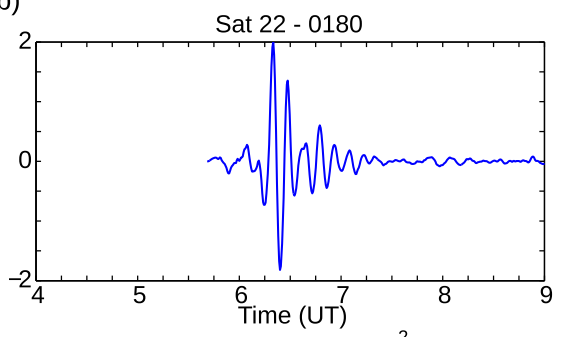

DSP $\max =3.02 \mathrm{TECU}^{2} / \mathrm{s}$

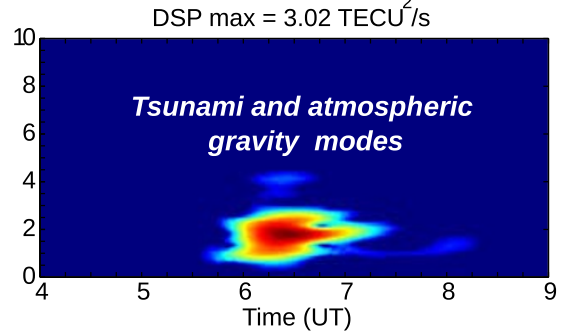

Fig. 3. Upper panel: two filtered slant TEC time series. Bottom panel: Corresponding spectrograms. (a) For station 0979 observing satellite 15 . It shows the primary gravito-acoustic pulse and two signals that oscillates with frequencies close to the two fundamental acoustic resonance frequencies $\left(S_{29}\right.$ and $\left.{ }_{0} S_{36}\right)$ at $\sim 3.7$ and $\sim 4.4 \mathrm{mHz}$. (b) For station 0180 observing satellite 22 . It shows a signal that oscillates with a dominant frequency of $\sim 1.8 \mathrm{mHz}$.

the epicenter) and are observed more than 2 hours after the main shock. This strong pattern is followed by a lower amplitude signal, with a horizontal propagation speed of about $170 \mathrm{~m} / \mathrm{s}$ (Fig. 2(b)), associated to the gravity waves forced by the tsunami.

These two waves are both characterized by a much slower vertical propagation than acoustic waves and need about 45 minutes to reach the ionosphere in the pure gravity case 
a)

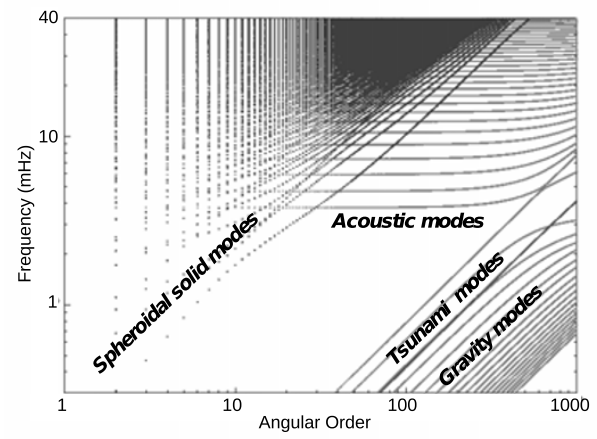

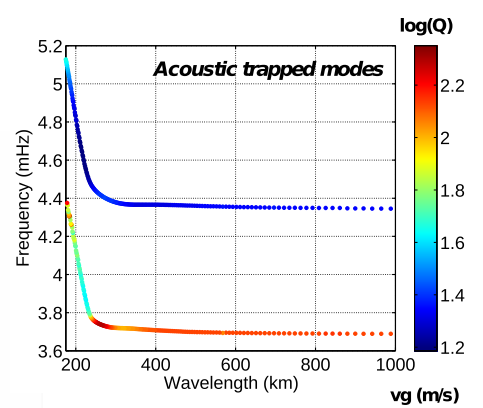

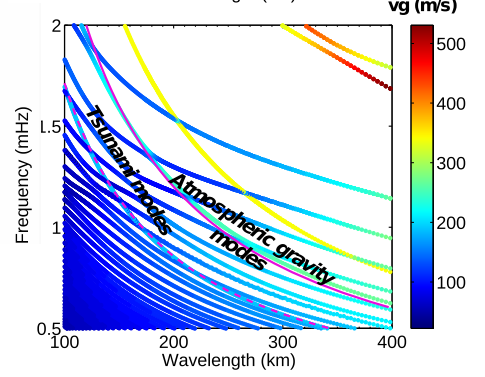

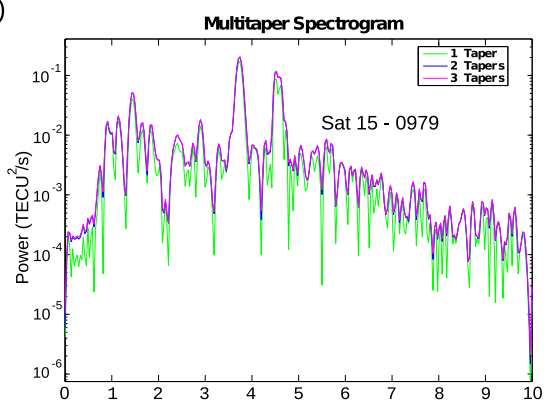

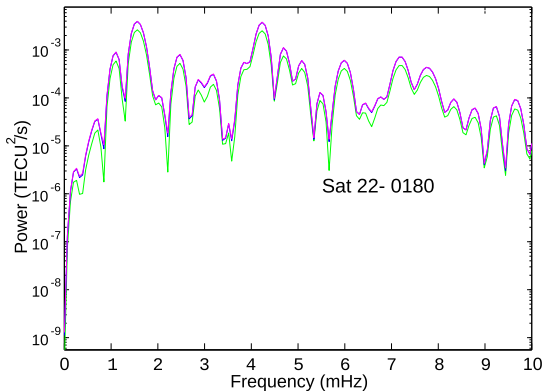

Fig. 4. (a) Left panel: dispersion curve (frequency versus angular order) of the modes of the Earth-atmosphere system, computed using a standard atmosphere model (USSA with free surface at $150 \mathrm{~km}$ ) and reprinted from Lognonné and Clévédé (2002). Right panel: zoom on the dispersion curves (frequency versus wavelength) of the two acoustic branches of trapped modes (up), with color-coded quality factor $Q$, and branches of atmospheric gravity modes (bottom), with color-coded group velocity $v_{\mathrm{g}}$, computed using the MSISE-00 (thermosphere of the day and radiating a surface at a $600 \mathrm{~km}$ altitude. The plain magenta line shows the atmospheric gravity modes that propagate at $\sim 225 \mathrm{~m} / \mathrm{s}$. The tsunami modes propagating at $171 \mathrm{~m} / \mathrm{s}$ are also shown in dashed magenta line. (b) Multitaper power spectrum of 4 hours starting after the shock wave for station 0979 observing satellite 15 on the top and for station 0180 observing satellite 22 on the bottom. The 3 first multitapers are used (Slepian, 1978). The first resonance is a peak at $3.73 \mathrm{mHz}$ which corresponds to the theoretical acoustic fundamental trapped modes of angular order of about 150 (about $265 \mathrm{~km}$ of wavelength) for the MSISE atmosphere of the day. The second peaks at about $4.5 \mathrm{mHz}$ and correspond to the first overtone. Note the doublet structure in this second resonance, a likely consequence of the vicinity of the theoretical first and second harmonics of the atmospheric wave guide e.g. Lognonné $e t$ al. (1998).

(Occhipinti et al., 2008, 2011), which explains why they appear at about $400 \mathrm{~km}$ of epicentral distance. Figure 4 shows the likely associated dispersion curves of these two waves, with a first one associated to free atmospheric gravity modes (continuous magenta line) and the second one associated to the tsunami modes (dashed magenta line). Note that the observed wavelengths are ranging typically from 150 to $200 \mathrm{~km}$ in the $1-2 \mathrm{mHz}$ bandwidth (Fig. 3(b)). More precise analysis will request correction for Doppler effects associated to the moving ionospheric sounding points and a better modeling of the attenuation effects.

Even if the observations of free gravity waves have already been reported several times after major earthquakes (see Bolt (1964), for the Alaska quake and Mikumo et al. (2008) for a review), the Japanese event reported here provides for the first time dynamic images of the propagation. If already observed at tele-seismic distances (see Rolland et al., 2010 and movie 2 for this event offshore Hawaii), it is also the first time that the tsunami induced gravity waves are observed so close from the epicenter.

We also note that the observed patterns have a clear northwestward directivity. However, previous observations over Japan of acoustic ionospheric waves have shown a directivity in the opposite direction, i.e. towards the SouthEast, due to the effect of the geomagnetic field (Heki and Ping, 2005; Rolland et al., 2011). Indeed the coupling factor between the neutral wave and the geomagnetic field is proportional to the cosine of the angle enclosed by the geomagnetic field vector and the wave vector (Calais et al.,
1998). As gravity waves are transverse and acoustic waves are longitudinal, the directivity of coupling effect in opposite directions seems coherent.

\section{Discussion and Conclusion}

By using GEONET GPS data, we have analyzed the ionosphere response to the Tohoku major earthquake of 11th March 2011. Our GPS-TEC data exhibit the appearance of three different types of waves in the TEC signal over Japan, in addition to the tsunami forced atmospheric waves. The first wave propagates at $\sim 3 \mathrm{~km} / \mathrm{s}$ and is, most likely, induced by the Rayleigh surface waves. However, part of this fast-propagating wave could also be directly related to the fault propagation. More in depth analysis of high-resolution (1-second) GPS data should help in validating one or both hypotheses. The second slower wave propagates at $\sim 1 \mathrm{~km} / \mathrm{s}$, and manifests the acoustic wave directly generated by the earthquake itself. These observations are in a good agreement with previous observations (Astafyeva et al., 2009; Rolland et al., 2011). For the first time in the Japanese area, we also observed appearance of a third type of wave. This third mode is a free gravity wave appearing in the TEC $\sim 45$ min after the main shock, from a distance of $\sim 400 \mathrm{~km}$ away from the epicenter. Its propagation speed was estimated to be $\sim 225 \mathrm{~m} / \mathrm{s}$ and frequency of about $1.8 \mathrm{mHz}$. These features are coherent with the observations of Maruyama et al. (2011) and Tsai et al. (2011) using GPSTEC technique and the observations of Liu and Sun (2011) in ionogram records. They are corroborated here by normal 
modes computation.

Further analyses of the very rich dataset presented here must be made, as their unprecedented quality will certainly provide new insights on the mechanisms taking place during the giant seismic rupture of the 2011 Tohoku Earthquake.

Acknowledgments. This work is supported by French Space Agency CNES. Additional supports were provided by the Campus Spatial Paris Diderot and the United States Office of Naval Research (ONR) globally under contract IONONAMI-N07-25. We thank the operators of the GEONET network for providing high quality data and T. Gabsi for support in data management. We also thank two anonymous reviewers for contructive comments. This is IPGP contribution number 3182.

\section{References}

Astafyeva, E. and K. Heki, Dependence of waveform of near-field coseismic ionospheric disturbances on focal mechanisms, Earth Planets Space, 61, 939-943, 2009.

Astafyeva, E., K. Heki, V. Kiryushkin, E. L. Afraimovich, and S. Shalimov, Two-mode long-distance propagation of coseismic ionosphere disturbances, J. Geophys. Res., 114, A10307, doi:10.1029/2008JA013853, 2009.

Bolt, B. A., Seismic air waves from the great 1964 Alaskan earthquake, Nature, 202, 1095-1096, 1964.

Calais, E., J. B. Minster, M. Hofton, and M. Hedlin, Ionospheric signature of surface mine blasts from Global Positioning System measurements, Geophys. J. Int., 132, 191-202, doi:10.1046/j.1365-246x, 1998.

Choosakul, N., A. Saito, T. Iyemori, and M. Hashizume, Excitation of four minute periodic ionospheric variations following the great Sumatra-Andaman earthquake in 2004, J. Geophys. Res., 114, A10313, doi:10.1029/2008JA013915, 2009.

Dautermann, T., E. Calais, P. Lognonné, and G. S. Mattioli, LithosphereAtmosphere-Ionosphere Coupling after the 2003 Explosive eruption of the Soufriere Hills Volcano, Montserrat, Geophys. J. Int., 179, 15371546, doi:10.1111/j.1365-246X.2009.04390.x, 2009.

Dučić, V., J. Artru, and P. Lognonné, Ionospheric remote sensing of the Denali Earthquake Rayleigh surface waves, Geophys. Res. Lett., 30, 1951-1954, 2003.

Dziewonski, A. M. and D. L. Anderson, Preliminary Reference Earth Model, Phys. Earth Planet. Inter., 25, 297-356, 1981.

Georges, T. M., Infrasound from convective storms: Examining the evidence, Rev. Geophys. Space Phys., 11, pp 571, 1973.

Heki, K. and J. Ping, Directivity and apparent velocity of the coseismic ionospheric disturbances observed with a dense GPS array, Earth Planet. Sci. Lett., 236, 845-855, doi:10.1016/j.eps1.2005.06.010. 2005.

Kanamori, H. and J. Mori, Harmonic excitation of mantle Rayleigh waves by the 1991 eruption of mount Pinatubo, Philippines, Geophys. Res. Lett., 19, 721-724, 1992.

Kobayashi, N. A, New method to calculate normal modes, Geophys. J. Int., 168, 315-331, 2007.

Kobayashi, N., H. Nagao, and Y. Fukao, Synthesis of wind-affected longperiod seismoacoustic waves, American Geophysical Union, Fall Meeting 2009, abstract \#A13D-0254, 2009.

Liu, J.-Y. and Y.-Y. Sun, Seismo-traveling ionospheric disturbances of ionograms observed during the $2011 M_{\mathrm{w}} 9.0$ Tohoku Earthquake, Earth
Planets Space, 63, this issue, 897-902, 2011.

Lognonné, P., E. Clévédé, and H. Kanamori, Computation of seismograms and atmospheric oscillations by normal-mode summation for a spherical Earth model with realistic atmosphere, Geophys. J. Int., 135, 388-406, 1998.

Lognonné, P. and E. Clévédé, Chapter 10: Normal modes of the Earth and Planets, in Handbook on Earthquake and Engineering Seismology, IASPEI Centennial Publications, edited by William, H., K. Lee, H. Kanamori, P. C. Jennings, and C. Kisslinger, International Geophysics series, 81A, 125-147, doi:10.1016/S0074-6142(02)80213-3, Academic Press, San Diego, 2002.

Lognonné, P., J. Artru, R. Garcia, F. Crespon, V. Dučić, E. Jeansou, G. Occhipinti, J. Helbert, G. Moreaux, and P. Godet, Ground-based GPS imaging of ionospheric postseismic signal, Planet. Space Sci., 54, 528540, doi:10.1016/j.pss.2005.10.021, 2006.

Lognonné, P., Seismic waves from atmospheric sources and Atmospheric/Ionospheric signatures of seismic waves, Ionospheric Seismology, in Infrasound Monitoring for Atmospheric Studies, edited by A. Le Pichon, Springer, 2009.

Makela, J. J., P. Lognonné, H. Hébert, T. Gehrels, L. Rolland, S. Allgeyer, A. Kherani, G. Occhipinti, E. Astafyeva, P. Coïsson, A. Loevenbruck, E. Clévédé, M. C. Kelley, and J. Lamouroux, Imaging and modeling the ionospheric airglow response over Hawaii to the tsunami generated by the Tohoku Earthquake of 11 March 2011, Geophys. Res. Lett., doi:10.1029/2011GL047860, 2011 (in press).

Maruyama, T., T. Tsugawa, H. Kato, A. Saito, Y. Otsuka, and M. Nishioka, Ionospheric multiple stratifications and irregularities induced by the 2011 off the Pacific coast of Tohoku Earthquake, Earth Planets Space, 63, this issue, 869-873, 2011.

Mikumo, T., T. Shibutani, A. Le Pichon, M. Garces, D. Fee, T. Tsuyuki, S. Watada, and W. Morii, Low-frequency acoustic-gravity waves from coseismic vertical deformation associated with the 2004 SumatraAndaman earthquake (Mw=9.2), J. Geophys. Res., 113, B12402, 2008.

Occhipinti, G., E. A. Kherani, and P. Lognonné, Geomagnetic dependence of ionospheric disturbances induced by tsunamigenic internal gravity waves, Geophys. J. Int., 173, 753-765, 2008.

Occhipinti, G., P. Coïsson, J. J. Makela, S. Allgeyer, A. Kherani, H. Hébert, and P. Lognonné, Three-dimensional numerical modeling of tsunamirelated internal gravity waves in the Hawaiian atmosphere, Earth Planets Space, 63, this issue, 847-851, 2011.

Slepian, D., Prolate spheroidal wave functions, Fourier analysis and uncertainty-V: The discrete case, The Bell System Technical Journal, 57, 1371-1430, 1978.

Picone, J., A. Hedin, D. Drob, and A. Aikin, NRLMSISE-00 empirical model of the atmosphere: Statistical comparisons and scientific issues, J. Geophys. Res., 107(A12), 1468, 2002.

Rolland, L. M., G. Occhipinti, P. Lognonné, and A. Loevenbruck, Ionospheric gravity waves detected offshore Hawaii after tsunamis, Geophys. Res. Lett., 37, L17101, doi:10.1029/2010GL044479, 2010.

Rolland, L. M., P. Lognonné, and H. Munekane, Detection and modeling of Rayleigh wave induced patterns in the ionosphere, J. Geophys. Res., 116, A05320, doi:10.1029/2010JA016060, 2011.

Tsai, H.-F., J.-Y. Liu, C.-H. Lin, and C.-H. Chen, Tracking the epicenter and the tsunami origin with GPS ionosphere observation, Earth Planets Space, 63, this issue, 859-862, 2011.

L. M. Rolland (e-mail: rolland@ipgp.fr), P. Lognonné, E. Astafyeva, E. A. Kherani, N. Kobayashi, M. Mann, and H. Munekane 